\title{
Software Design of Building Material Quality Monitoring System based on Windows CE
}

\author{
Zhigang Feng and Ming Gu \\ School of Automation, Shenyang Aerospace University, Shenyang, Liaoning, China \\ fzg1023@yeah.net
}

\begin{abstract}
Construction industry is one of the important pillar industries of our national economy. The quality of building products is very important to the safety of people's life and property. The quality of building materials is directly related to the quality of construction products. And building materials testing work is very complicated, the data and accuracy requirements should be detected efficiency, the testing result should be fair, scientific. Therefore, the rapid development of the industrialization system and the construction industry, the quality of the construction materials put forward new requirements, also is bound to the construction material quality inspection and supervision brings new challenges. The widely use of automatic equipment and the application of computer technology make the process of quality inspection more scientific and fair. This paper mainly discusses the design and implementation of building material quality monitoring software. This paper gives a detailed design scheme to achieve data acquisition, transmission and preservation. Finally give the design scheme and realize the function of the whole monitoring software.
\end{abstract}

Keywords: Construction Materials, Quality, Monitoring Software, Windows CE Platform

\section{Introduction}

The important project, quality first. During the supervision process of the construction project, the test data of building materials [1,2] is an important basis for judging the quality of the building. It can be seen that the quality inspection and monitoring of building materials is one of the important parts to control building quality. The monitoring object is the building materials which mainly the purchase of raw materials or products and on-site processing materials. For the materials or products been purchased, must be carry out inspection and monitoring. For field processing and prepared material, need for quality control and monitoring especially. Quality supervision and inspection of building materials is the core of project quality management, is a strong technical and a major responsibility of the key work. All kinds of building materials quality monitoring body is the government or the public's trust. Through the construction of various types of construction materials and construction materials used to monitor, provide fair, scientific and accurate quality data to the public, to realize the supervision of engineering quality.

Monitoring department in the monitoring of construction materials' quality, previously, was done manually to manage a large number of monitoring data and management information for effective treatment to achieve monitoring data collection, processing, delivery and issue a report, a large amount of information transmission, data processing (Including the calculation, selection and rounding etc.). Want to be accurate, fast, beautiful, reducing human error is not easy, to realize the scientific, fair and effective of the inspection report data will be discounted, scientific management of the monitoring work, reduce the labor of the monitoring personnel, improve work efficiency is more important. 
In this paper, the software design and implementation of building material quality monitoring system are described in detail. Section 2 gives the overall architecture of the system. Section 3 introduces the hardware system design and implementation detailed. Section 4 introduces the software design and implementation in detail. Section 5 gives the experiment and results.

\section{Overall Design of the System}

This paper designs and develops a set of quality monitoring system for building materials. The topological structure of the system is shown in Figure 1. System include: data acquisition part, data acquisition system, processor chip microcomputer, sensor, routers and other. Sensor and data acquisition part is the quality data monitoring part of the system. The information management software running on the PC machine is the information management part. The switch and the software running on the PC form the process monitoring part. Quality monitoring part is responsible for receiving the collected data and data processing, display and send to the information management part; the information management part is responsible for the reception of the experimental data to be drawn into curves and stored in the database.

A perfect building material monitoring system not only has many channel real-time collection, but also needs to improve the data management capabilities. The software of system mainly includes two parts: multi-channel data acquisition and building materials monitoring data management software. Additional, the system supports real-time many channel acquisition and remote acquisition.

The data acquisition from data acquisition could be divided into two parts: pressure or tension and displacement. The requirement analysis of the building materials data monitoring software is described as follows:

(1) Multi-channel real-time detection Responsible for receiving data acquired from data acquisition part;

(2) Data interface rendering Responsible for displaying the data and parameter settings of the specified collector;

(3) Data forwarding Responsible for forwarding data to the host computer.

This paper mainly research Windows CE quality monitoring data acquisition software for building materials, research network port upload data program design, receiving serial data programming. Serial data include pressure, displacement, decoding, display, simple calculation, data storage, raw data and calculation results are transmitted to the host computer via the network. Sensor calibration interface include the encoder calibration, parameter settings, user management and password settings.

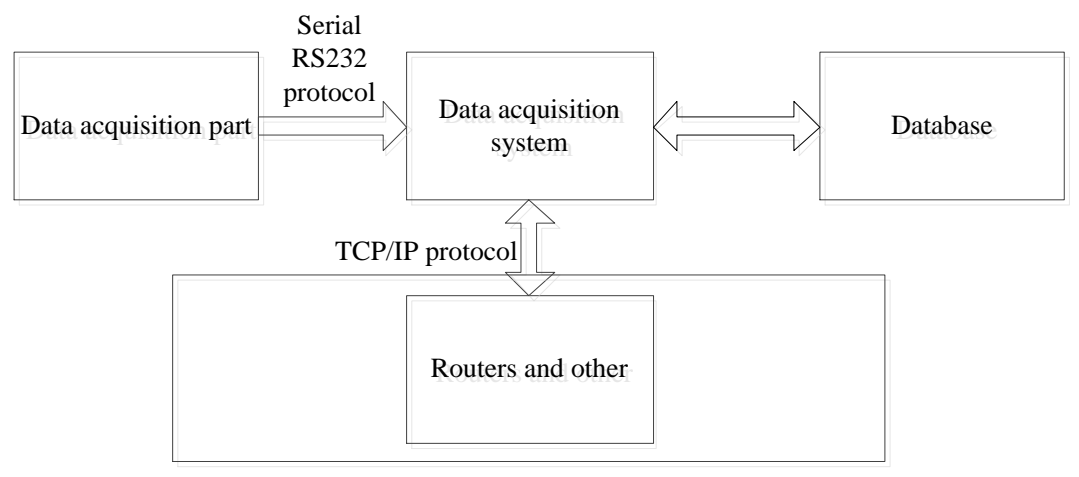

Figure 1. Functional Block Diagram 


\section{Hardware Design of the System}

The hardware of the system has two parts: the embedded platform and the data acquisition part.

\subsection{Embedded Platform}

The environmental of system works requirements the device is based on industrial monitoring and is easy to carry easy to use. The device which monitoring software running on must has advantages as operation stable, high speed; secondly, the software development based on embedded Windows CE platform has irreplaceable important meanings: Embedded system is an electronic products which the software and hardware system with the core of the micro controller is embedded[3,4,5]. The hardware of the embedded system includes the design of the circuit and the circuit board; embedded system software includes system instruction, development of embedded application software and the development of various scripts and software, management software. Embedded operating system management and control the software and hardware resources which are the same as general computer operating system, reasonable and efficient allocation of shared computer resources. The different is embedded operating system in embedded environment. This forms its unique characteristics:

(1) In order to meet the requirements of product design, the system function can be adjusted and tailored according to the application requirements. The loading and unloading of the embedded operating system;

(2) The functional purpose of the embedded operating system is determined and its goal is to accomplish a specific function of a specific or limited term;

(3) Reliability, cost and energy are the important factors in embedded system, which has become one of the essential characteristics of embedded operating system;

(4) The embedded system resources are limited, so the embedded operating system must occupy the resources as little as possible, in order to secure and stable operation in the limited storage space;

(5) Good portability, can better adapt to different hardware systems

The hardware platform environment had been chose has such factors:

$>$ CPU: ARM9 embedded low power CPU, dominant frequency 400MHz;

$>$ Memory: Standard Version 128M DDR2 SDRAM;

$>\quad$ Storage device: 256M Flash;

$>\quad$ Extended storage: SD card store maximum support extended to $32 \mathrm{G}$;

$>\quad$ Measured power consumption: Less than 3W;

$>$ Power input: DC 9V-24V;

$>\quad$ Interface:2 RS-232 interface;1 RS-485 interface;2 USB main port;1 USB from the mouth;1 network interface;

$>\quad$ Other: Built in RTC real time clock; Watchdog management; built in buzzer, Provide a function to control the sound, Anti surge, anti-lightning, anti-reverse, over current protection, wide voltage;

$>\quad$ Working temperature: $-10^{\circ} \mathrm{C}-60^{\circ} \mathrm{C}$

$>$ Working humidity:20\%RH-95\%RH

\subsection{Microcontroller Data Acquisition Part}

In this system, the data collector is needed to acquire two types of signals: force and displacement. After data processing, the data processing is transmitted to the PC through Ethernet. In addition, the PC machine can be set up through the serial port to the data collector. For this design data acquisition function module is shown in Figure 2, including: power module, data acquisition module, processor module, serial port module, Ethernet module, display module, keyboard module. 


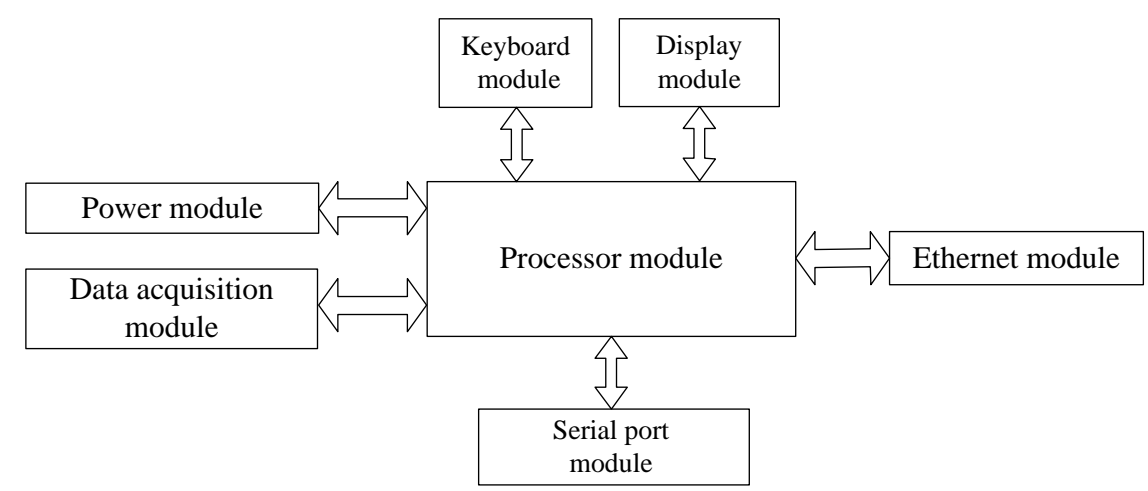

Figure 2. Main Function Modules of Data Acquisition System

Power module is responsible for data acquisition power supply. The data acquisition module is responsible for the processing of the signal of the sensor and the operation of the amplifier. Processor module is responsible for processing sensor signal displays the processing results on the display module and Send to the PC by the Ethernet module. The serial module is responsible for receiving the setting information of PC and completes data acquisition information settings. The display module is responsible for displaying the current detection information and information. Keyboard module is responsible for setting parameters.

\section{System Software Design}

The system software design is mainly divided into three parts, the first module is the test function module, the second module is the system parameter setting function module and the third module is the other function modules.

Windows CE system development [6]: The development of Windows CE system is essentially a development of embedded system and the embedded system is composed of hardware and software, operating system and application software. As shown in Figure 3, embedded system development is different from the development of the PC, as a complete Windows CE based system development is made up of hardware development and software development.

(1) BSP design of the underlying software

\begin{tabular}{|c|}
\hline Application software \\
\hline Windows CE operating system \\
\hline BSP software \\
\hline Hardware components \\
\hline
\end{tabular}

Figure 3. Windows CE System Developments

When we build the hardware platform, we need to make the Windows CE operating system on the hardware stable operation. Microsoft Corps technical staff to consider is the design of the Windows CE operating system on the different architecture of the hardware platform for the transplant operation, this requires hardware manufacturers (OEM) in accordance with the Windows CE to support the development of the interface and the interface of the underlying software, the popular talk is a variety of drivers.

(2) Custom operating system Windows CE 
When the BSP package development successfully completed, behind the work is mainly through the use of powerful development tools provided by Microsoft for the development of windows CE operating system. Platform Builder integrated development environment to tailor and customize the operating system can be run. If the user is not satisfied with the functional components provided by Microsoft, it can be customized according to the design requirements, such as the development of a specific interface, a custom browser, etc.

(3) Development of monitoring software

Monitoring software development this part is our main development content, below we want to introduce this part of the content in detail.

\subsection{System Main Interface Design}

The upper left corner for the project encoding static control, test number of static control, set the number of static controls, the left side of the data display, the lower left corner of the control, the lower right corner of the information state static control, display machine code information, operator information, test temperature information, network state information, the interface between the main interface, display data curve real-time information.

\subsection{The System Function Design}

The setting of software is as follows: the software is the data acquisition system of building material quality testing data acquisition software running on the data acquisition system. Load and displacement measurement, collection, display, storage and transmission function of building materials, including the test number, item encoding, group number; test results shows the real-time load, real-time displacement, limit force displacement, limit load, loading rate and yield load value, when in [Settings] select [Collector show], in the load displacement curve of the interface shows the calculated results above the yield strength and tensile strength, in test set at the same time, the corresponding input bar diameter, otherwise the results will prompt information error; according to the collector state, testing process gives some information, including data uploaded upload data, failure, overload alarm; information collector section shows some system information of the acquisition, including the collector number, the maximum measurement range, the selection range, test temperature, the operator, the network state; the load displacement curve shows the reinforcement in the real-time load and displacement curve of the test process and test in the end. After the calculation and draw up and down the yield value.

Parameter setting interface design: parameter setting interface display function button controls, including the test set the button control button control, sensor calibration, the measurement range selection button controls, button controls, collector set curve setting button controls, button controls, encoder settings button control button control, historical data, user management button controls, equipment use determine the record button controls, button controls, cancel button controls, add member variables, related news function, complete function button controls design, then the test set interface, sensor calibration, the measurement results, the range selection interface, collector set interface, curve setting interface, the encoder interface settings, historical data interface, the user management interface, device using the recording interface, the interface design, cancel, generally use the static text control, the text edit control, button control, drop-down list box etc.

SQLITE database[7,8,9]: database using SQLITE database, database tables, including user management table, the history of the management table, the use of equipment records management table, bar data sheet, a roller type bending data sheet, cement data sheet, add 
the database field. The main functions of the software are shown in Figure 4. The Function modules of each part are shown in Figure 5, Figure 6 and Figure 7.

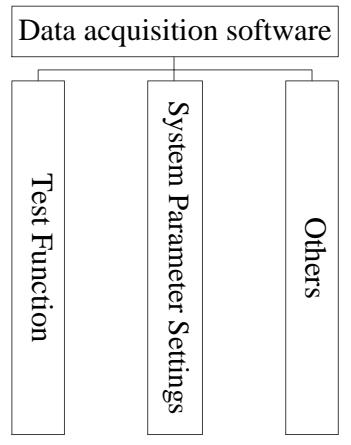

Figure 4. Functional Block Diagram of Software

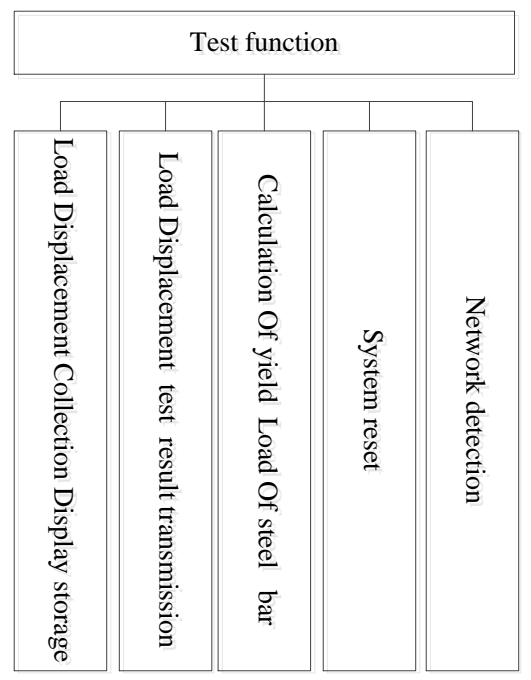

Figure 5. Functional Block Diagram of Testing Function

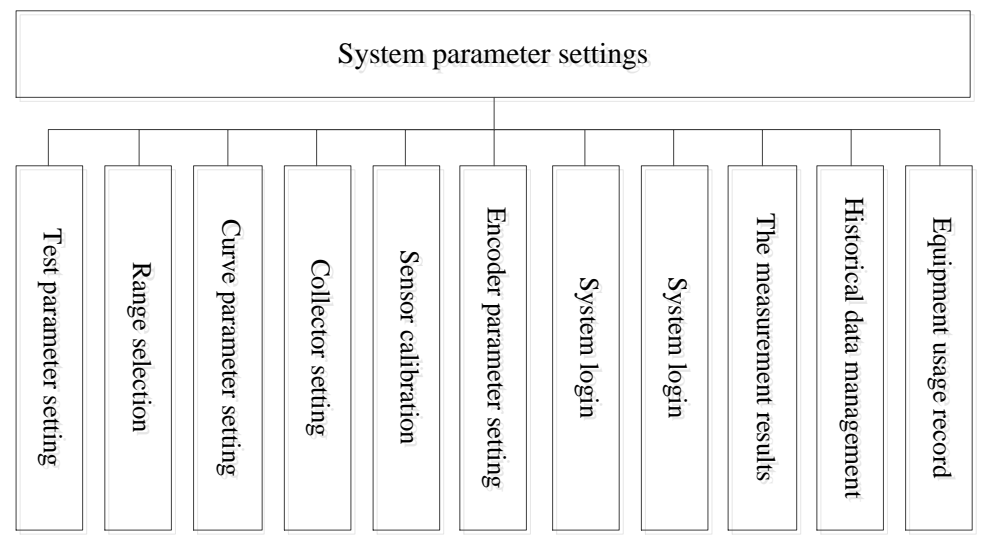

Figure 6. Functional Block Diagram of System Parameter Settings 


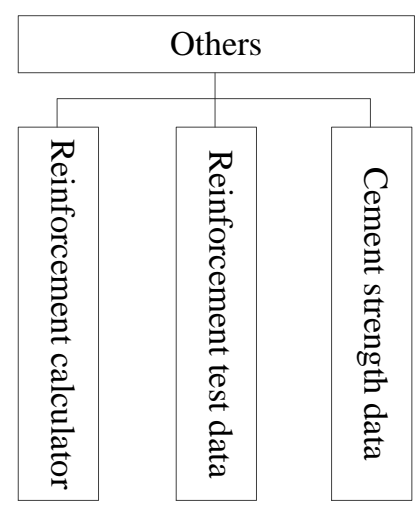

Figure 7. Functional Block Diagram of Other Functions

\subsection{The Flow Chart Design of the System}

\subsubsection{The Main Flow Chart of System}

Test function module: load displacement collection display storage, test results transmission, steel yield load calculation, system reset and network detection. Software function flow chart is shown in Figure 8.

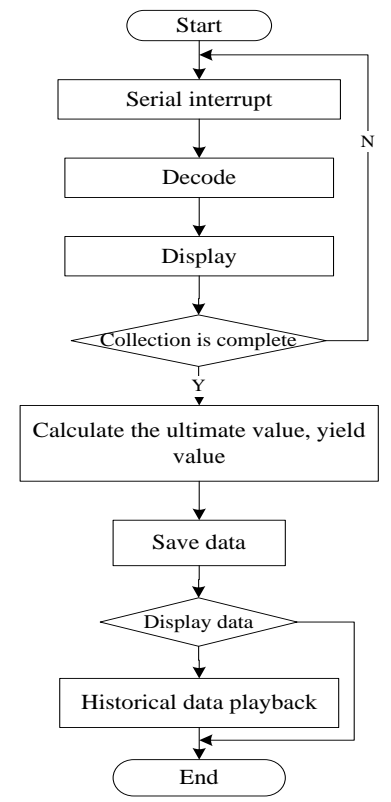

Figure 8. The Flow Chart of Whole System

\subsubsection{System Parameter Setting Module}

Set the test parameters, selection range, curve parameter setting, collector is arranged, sensor calibration, encoder parameter setting, system log in, the user management, the measurement results, historical data management, facility use record. Test parameters settings: set up the interface to enter the test parameters , complete the test, parameters setting, including the project encoding, test year, test number, group number and maximum group number and the number of steel bars, set the diameter of the steel, set the length and width of the test piece, click on the button to cancel the setting. 
Range selection: in the setting of the interface click on the [Range selection] button to enter the range select interface, select the appropriate measurement range, click the corresponding range button and click on the button to select the appropriate range for this test.

Curve parameter settings: in the setting of the interface click on the button to enter the curve to set up the interface, select the type of curve and the range of curve coordinates.

Encoder parameters setting: in the settings screen, click the [Encoder parameters set] button to enter the encoder parameters setting interface, the threshold used to set the system to judge the beginning measurement threshold, the encoder readings show realtime encoder data, the displacement input by the user, the encoder zero for zero photoelectric encoder.

System log in: after the collector starts, first enter the system log in interface, select the user name, enter the user password, enter the current temperature and device status, click OK button to enter the acquisition interface.

User management: in the setting of the interface click [User management] button to enter the user interface, to add users, delete users and modify user password operation.

The measurement results: in the setting of the interface click on the results of this measurement button or press 8 key in the main interface, you can view and modify the results of the test results, the corresponding test results, and the test results will be saved to the database and uploaded to the server.

Historical data management: in the setting interface click on the historical data management interface, enter the historical data management interface, click on the button query reinforcement test results, click on the non-reinforcement test results, select the test results, click on the selected test results sent to the server, select the test results, click delete, delete the selected test results.

\subsubsection{Other Functional Modules}

Other functional modules: reinforced calculator, reinforced test data, cement force data. Server software running on the data server to achieve real-time display, storage and management functions of data acquisition data, to achieve the management of the data collector, the software support through the LAN and WAN connection to the software.

According to the different requirements of different sensors, the calibration value of the sensor is calculated and the accuracy of the calibration process is achieved, the calibration flow chart is shown in Figure 9.

(1) Click on [20\%], [50\%] or [100\%] to select the range to be calibrated.

(2) Enter the standard value according to the selected range value.

(3) will position the cursor to the loading to calibration value corresponding to the actual voltage value, to press pressure to the standard loading value, at this time of the voltage value is corresponding to the standard loading value of the voltage value.

(4) will move to under a to calibration loading value corresponding to the actual voltage value position, to press pressure to the standard loading value, completed the calibration under a standard load value, in accordance with this method complete the calibration.

(5) after all the measuring range is complete, click on the [save] button to save the calibration data. 


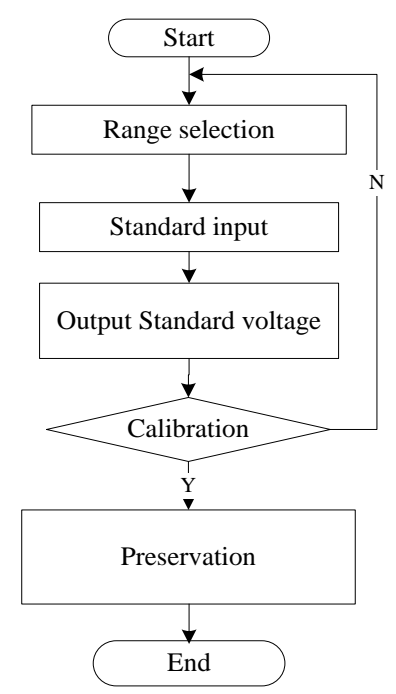

Figure 9. The Calibration Flow Chart

\section{Experimental Results and Analysis}

This software is the construction material quality monitoring data acquisition software. Running on the data acquisition, the realization of the construction of load and displacement of the load and have displacement measurement, collection, display, storage and transmission functions.

In the main interface click [Setting] button to enter the system parameters setting interface which is shown in Figure 10, you can set the test parameters, system parameters and user and test results of the management functions.

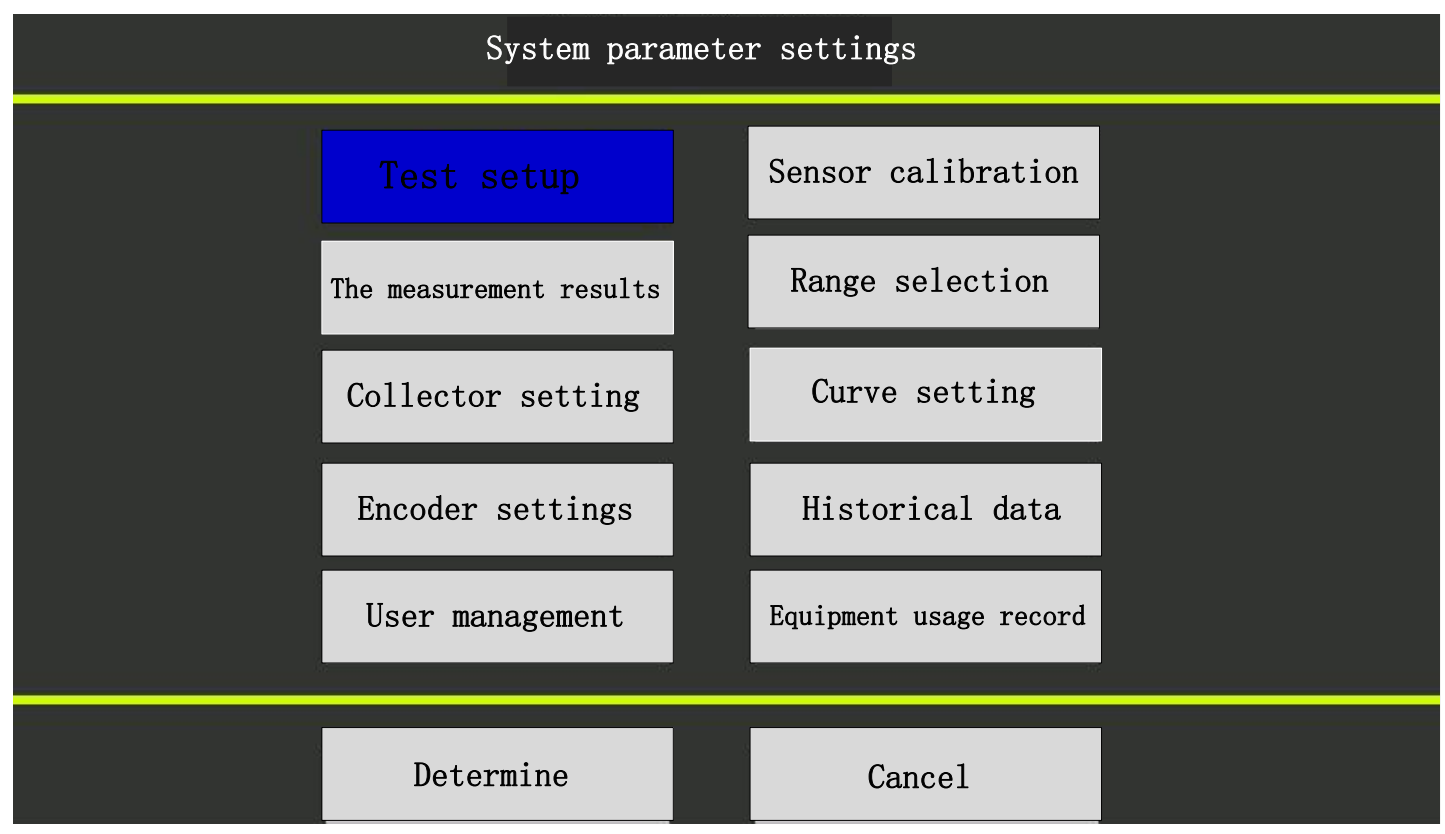

Figure 10. The System Parameter Setting Interface

The load displacement interface as shown in Figure 11, mainly used in steel test, test information section shows the details of the test. 


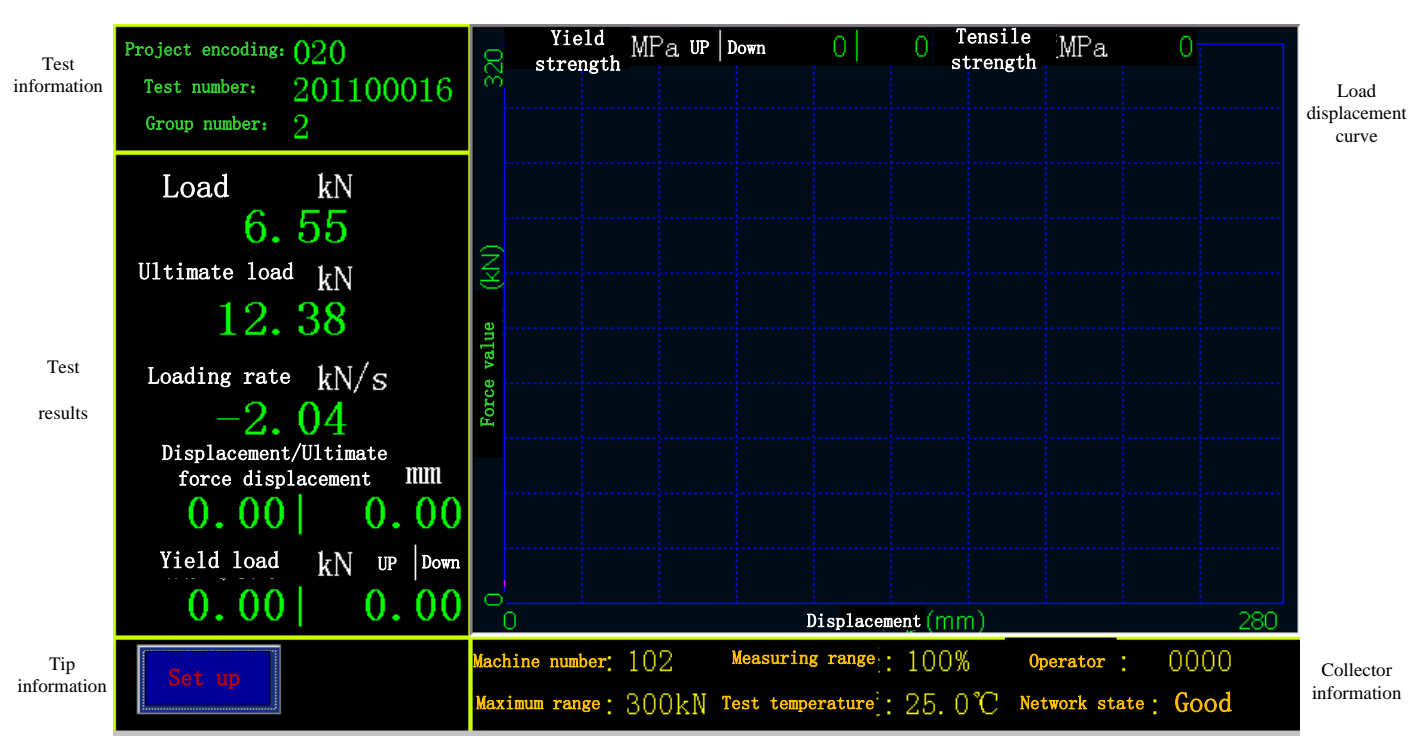

Figure 11. The Load Displacement Interface

Load time interface is shown in Figure 12, mainly used for non-steel or steel test in the case of displacement sensor damage. The testing information and the test results is same with the collector information part of the same load displacement interface, load time curve shows the real-time load and time curve.

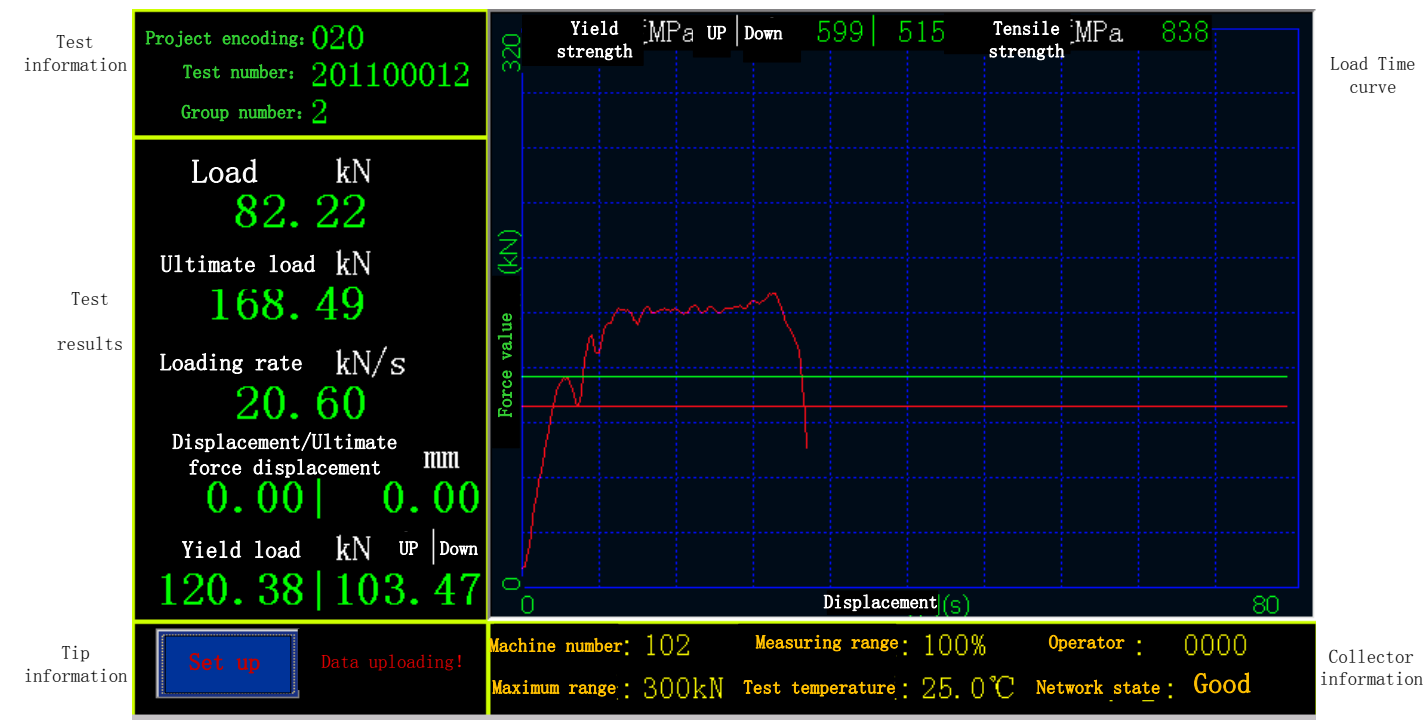

Figure 12. The Testing Load Time Interface

The real-time data interface as shown in Figure 13. It is mainly used for non-steel test piece or collector verification process, the test information part of the test results, suggesting that information part and the collector part of the information is the same as the load displacement of the interface, real-time testing information to big size display real-time load, ultimate load and loading rate. When the collector is set to select the display results, the compress strength of the results will be displayed and the test set is required to enter the corresponding test piece length and width, otherwise the result will be wrong. 


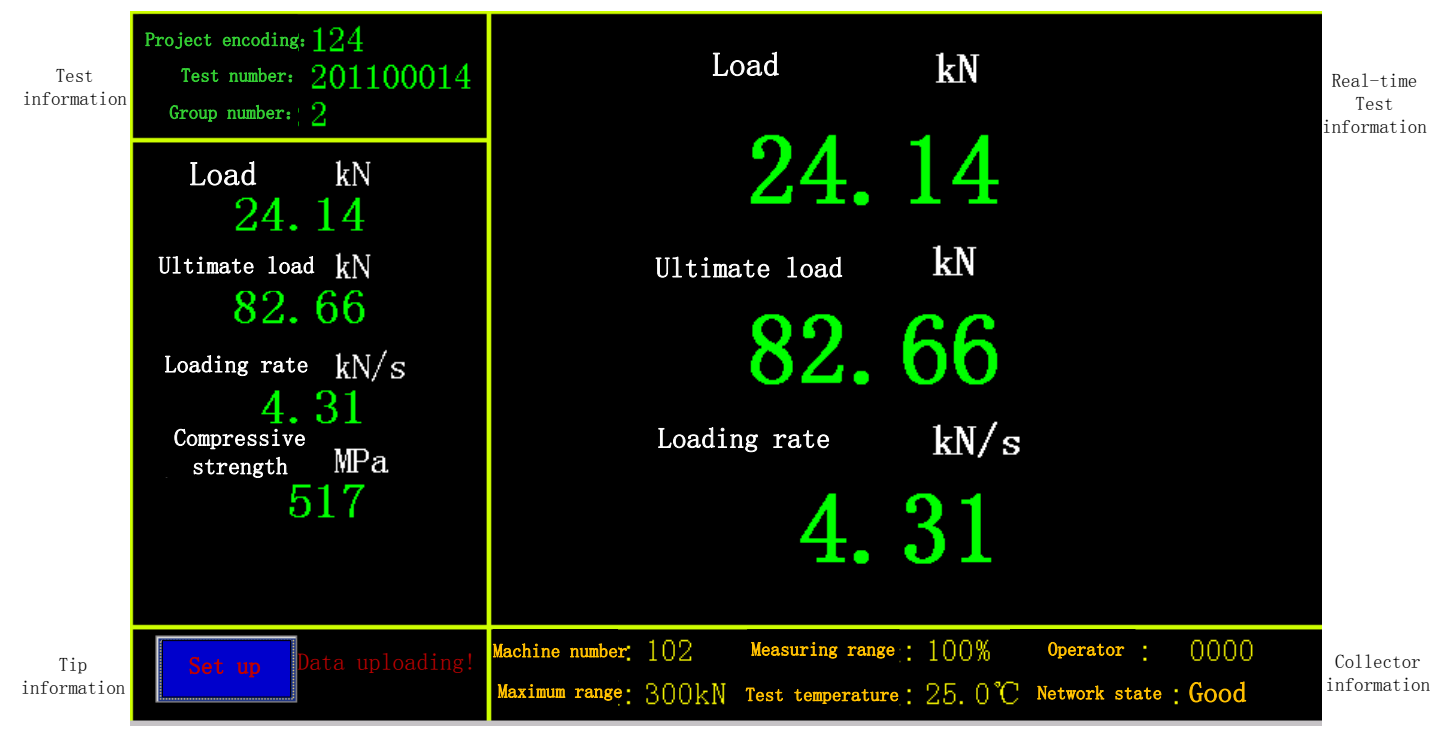

Figure 13. The Real-Time Data Interface

The collector setting is shown in Figure 14. In the setting of the interface click [Collector settings] button to enter the collector settings interface to set the collector ID, maximum range, the machine IP address, sub net mask, gateway, server IP address or domain name and port. Then the Building material quality monitoring management system software will running on server of PC. At the same time, it can set up the network, whether the yield strength, tensile strength or compress strength.

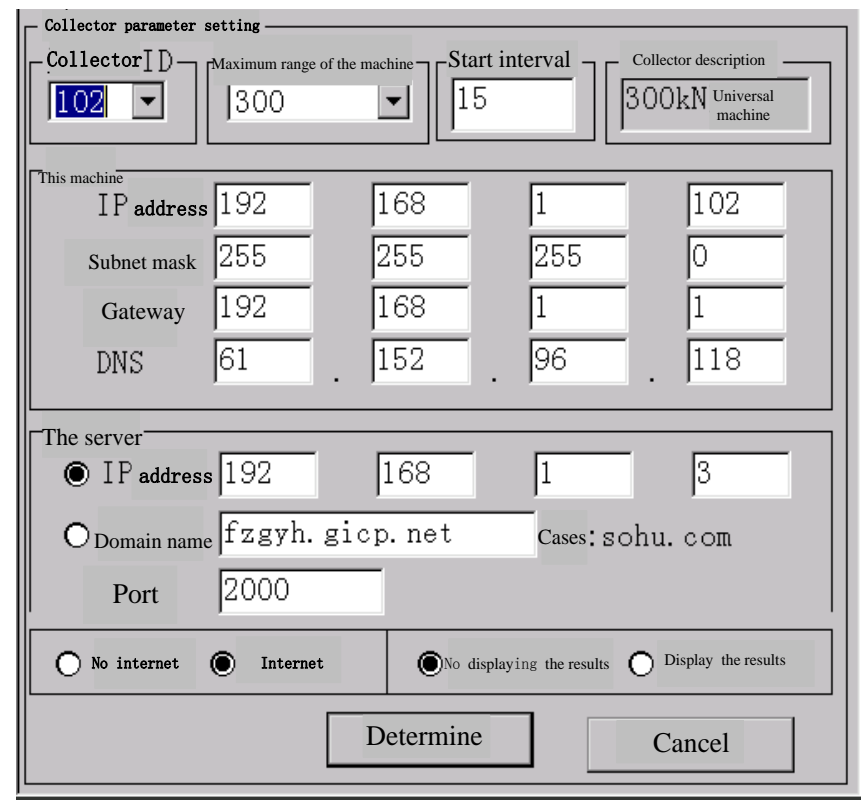

Figure 14. The Collector Settings Interface

The sensor calibration interface is shown in Figure 15. In the setting of interface click on the [Calibration] button to enter the sensor calibration interface, the current measurement value of the real-time voltage and the use of the current calibration data calculated from the standard load value of the standard load value, the actual voltage value is collected from the collector to the corresponding standard value of the voltage value. 


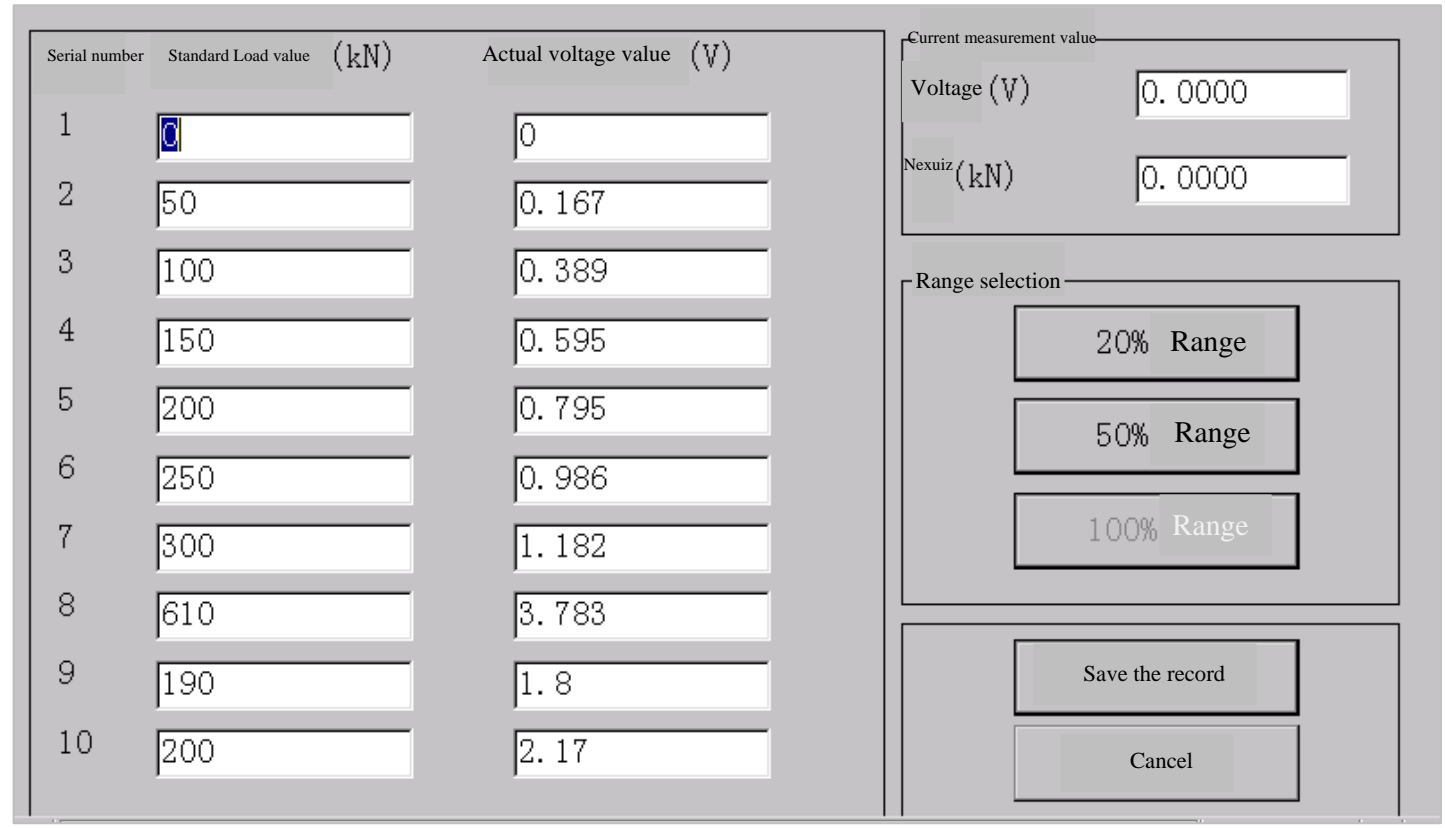

Figure 15. The Sensor Calibration Interface

In the setting interface, click on the [historical data] button enter the historical data management interface which is shown as Figure 16. And click on the query steel button to check the results of the reinforcement test; click on the non-reinforcement test results; select the test results, click on the selected data, will select the test results to the server; select the test results, click on the delete, delete the selected test results.

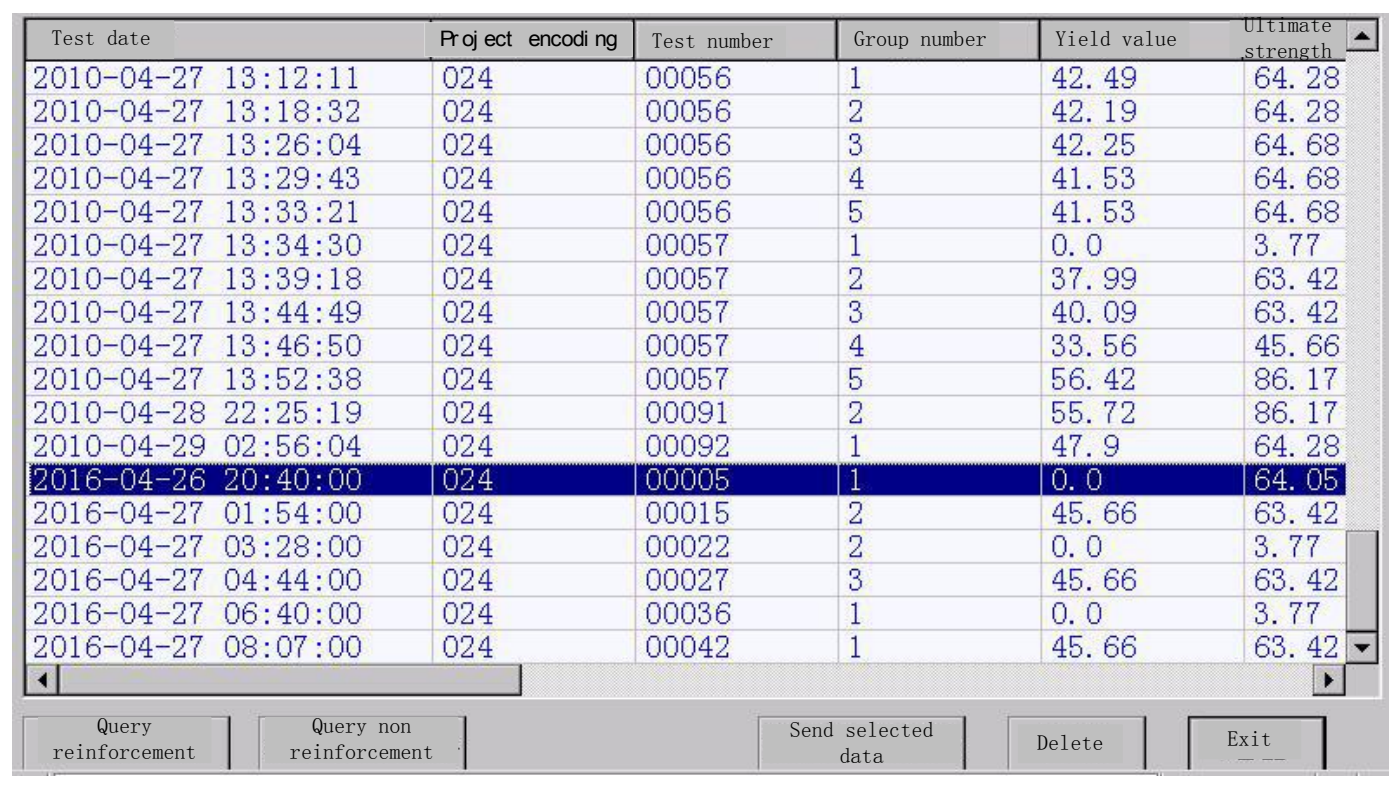

Figure 16. Historical Results Management

\section{Conclusions}

Through the analysis of the above experimental results, the design requirements are accomplished and the measurement, collection, display, storage and transmission function of the load and displacement of the building materials are achieved by the verification of 
the design function.VS2005 has the advantages of simple interface, short development cycle, low investment, high reliability, strong function and has been successfully applied to a building material quality monitoring station. System operation practice shows that the time of searching information is greatly reduced and the work efficiency is greatly improved and the operation of building materials quality inspection department provides accurate and complete data of building materials, to promote scientific management of building materials.

\section{Acknowledgements}

The authors would like to thank the financial support of the financial support of the 2014 high school talent support plan second levels of Liao Ning province China. LJQ2014017.

\section{References}

[1] Z. Feng, F. Dai and H. Yang, "Development of building material monitoring and management system based on W5200 and C8051F060", 2013 International Conference on Advanced Technologies and Solutions in Industry, March 22-23, Taiyuan, Shanxi, China,(2013), pp. 496-500

[2] S. Guo, B. Du, L. Sun, Y. Li and J. Guo, "Design and implementation of digitization management platform for manufacturing enterprises of building material equipment", Jisuanji Jicheng Zhizao Xitong/Computer Integrated Manufacturing Systems, vol.21, no.1, (2015), pp.226-234

[3] S. Li, J. Tian, H. Kui and H. Wang, "Design and implementation of vehicle monitoring and earlywarning system based on WinCE", 2011 International Conference on Electric Information and Control Engineering, Wuhan, China, (2011), pp. 2073-2076.

[4] G. Qi and P. Sun, "The embedded system design for military or industry personal data assistant", International Journal of Advancements in Computing Technology Abbreviated source title, vol.4, no.23, (2012), pp.226-233.

[5] Y. Liu, Z. Wang and W. Su, "Measurement of ship distributed deformation based on embedded system", Guangxue Jingmi Gongcheng, vol.23, (2015), pp.247-252.

[6] Y. Hu, P. Wu, W. Wan and L. Guo, "Design for PDA in portable testing system of UAV's engine based on wince", 2011 International Conference on Computing, Information and Control, Wuhan, China, (2011), pp.452-457.

[7] D. Chen, X. Han and W. Wang, "Use of SQLite on embedded system", 2010 International Conference on Intelligent Computing and Cognitive Informatics, Kuala Lumpur, Malaysia, (2010), pp.210-213.

[8] Q. Gu and X. Cheng, "Study and application of SQLite embedded database system based on Windows cE", 2nd International Conference on Information Science and Engineering, (2010) December 4-6; Hangzhou, China, pp.6920-6923.

[9] K. Yue, L. Jiang, L. Yang and H. Pang, "Research of embedded database SQLite application in intelligent remote monitoring system", 2010 International Forum on Information Technology and Applications, Kunming, China, (2010), pp.96-100.

\section{Authors}

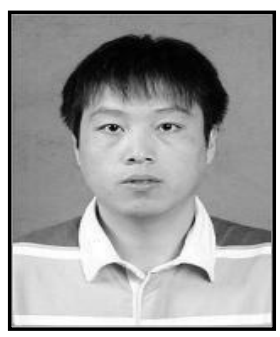

Zhigang Feng, he is an associate professor of Shenyang Aerospace University. He received his Doctor's Degree from Harbin Institute of Technology, P.R. China at 2009. His main research direction includes system fault diagnosis, self-validating sensor and self-validating actuator. 


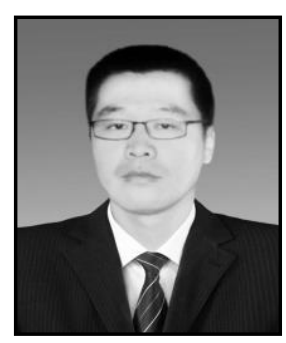

Ming Gu, he received the bachelor degree of Communication Engineering from Chengdu University of Information Technology, China, in 2007. He is currentlystudying for a master degree in the School of Automation, Shenyang Aerospace University. 